\title{
Electrochemical Study and Determination of All-trans-Retinol at Carbon Paste Electrode Modified by a Surfactant
}

\author{
Simona Žabčíková, \\ Tomáš Mikysek, Libor \\ Červenka and Milan Sýs*
}

Department of Analytical Chemistry, Faculty of Chemical Technology, University of Pardubice, Studentská 573, CZ-53210 Pardubice, Czech Republic

Received: 22 November 2017 Accepted: 9 May 2018

\section{(c) (i) (9)}

${ }^{*}$ Corresponding author:

Phone: +420466037068;

Fax: +420466037279;

E-mail:milan.sys@upce.cz

\section{SUMMARY}

The oxidation mechanism of all-trans-retinol (vitamin $A_{1}$ ) and its several esters in non-aqueous, aqueous organic mixture, and pure aqueous media was investigated by cyclic voltammetry. The oxidation occurred in several irreversible steps. The calculated highest density of electrons in retinoid molecules which are delocalized over carbon atoms of the five conjugated double bonds ( $\mathrm{C} 5-\mathrm{C} 14$ ) was found in the part of the molecule involved in oxidation processes. The most sensitive oxidation peak ( $\mathrm{at}+0.8 \mathrm{~V} v \mathrm{~s}$. $\mathrm{Ag} / \mathrm{AgCl}$ ) was used for development of new direct voltammetric method based on differential pulse voltammetry for the determination of retinol at carbon paste electrode modified with surfactant sodium dodecyl sulfate (CPE/SDS). The results show that $30 \%$ (by mass) of modifier SDS exhibited optimal sensitivity and shape of voltammograms. Compared to commonly used glassy carbon electrode (GCE), the CPE/SDS showed significant progress in the retinol electroanalysis. The linear ranges for retinol determination were $1.5 \cdot 10^{-6}-1.8 \cdot 10^{-4} \mathrm{M}$ for CPE/SDS and $4.4 \cdot 10^{-6}-7.0 \cdot 10^{-4}$ $\mathrm{M}$ for GCE with the detection limits of $1.3 \cdot 10^{-6}$ and $4.6 \cdot 10^{-7} \mathrm{M}$, respectively.

Key words: modified carbon paste electrode, differential pulse voltammetry, glassy carbon electrode, all-trans-retinol, surfactant

\section{INTRODUCTION}

Retinol, known as vitamin $A_{1}$, belongs to the group of fat-soluble vitamins generally classified as vitamin A (carotenoids), D (cholecalciferols), E (tocopherols) and K (naphthoquinones). Deficiency (avitaminosis) of vitamin A leads to the night blindness or keratinization of cells. It is often a disease of children, especially occurring in the developing countries. On the other hand, its surplus (hypervitaminosis) can cause poisoning, especially teratogenesis. However, it is important that the content of vitamin A in foodstuff and food supplements is very low $(1,2)$. For that reason, the poisoning caused by overdosing is rare.

In a narrower sense, it belongs to a group known as retinoids, which are essential substances. Usually, retinol is degraded by oxygen, high temperature or light exposure. The content of vitamin A in foodstuffs depends on good storage and packaging, thus the content of retinol can be an indicator of freshness of food or of the good storage conditions. Synthetic retinoids such as retinyl acetate and retinyl palmitate usually serve as food additives due to their higher stability $(2,3)$.

From chemical point of view, molecule of retinol contains conjugated double bonds. Hence, standard procedure of retinol determination is spectrophotometry in visible spectrum at $620 \mathrm{~nm}$ or in UV spectrum ranging from 310 to $325 \mathrm{~nm}$. These properties allow nowadays routine UV detection in the liquid chromatography (4-6). Moreover, descriptions of chromatographic methods utilizing diode array $(7,8)$ or electrochemical detection already exist (9). Retinol detection is possible by capillary zone electrophoresis with laser-excited fluorescence detection, even directly in a blood sample (10). For all these methods, complex sample preparation is necessary, which requires time-consuming analysis and economically demanding instrumentation.

Unlike this, direct conventional voltammetric methods offer certain alternatives to how to eliminate the already mentioned disadvantages (11-15). On the other hand, the lipophilic 
character of retinol represents the main problem of its electrochemical determination. Thus, all previously developed methods were performed at solid electrodes in organic solvents, aqueous-organic mixtures, or aqueous surfactant solutions (11-15).

Common carbon paste electrodes in non-aqueous media have low mechanical stability $(16,17)$, hence their composition has to be changed by selection of: (i) highly viscous paste binder, (ii) special carbonaceous material, namely glassy carbon powder, and (iii) surfactant modification. The last one is a type of carbon paste electrode (CPE) introduced by R. N. Adams in 1965 (18), where the regular carbon paste was modified with $30 \%$ (by mass) sodium dodecyl sulfate (SDS). Generally, the presence of surfactants effectively repells molecules of organic solvent from the electrode surface (19).

Bare glassy carbon paste electrode (GCPE) applicable in an extractive stripping voltammetry of tocopherols (vitamin E) and CPE (or GCE) covered with thin layer of carbon nanomaterials represents another example of using carbon-based electrodes in the monitoring of lipophilic vitamins (20-22).

This study presents the above-mentioned carbon paste electrode modified with SDS (CPE/SDS) in voltammetric determination of all-trans-retinol using $0.1 \mathrm{M} \mathrm{LiClO}_{4}$ in $99.8 \%$ acetonitrile as supporting electrolyte. Moreover, it offers comparison of CPE/SDS behaviour with regular glassy carbon electrode (GCE; 20 ) in determination of retinol by differential pulse voltammetry (DPV). Additionally, electrochemical studies of retinol and its esters (retinyl acetate and retinyl palmitate) in used supporting electrolytes were performed in order to confirm or disprove the previously proposed reaction mechanisms.

\section{MATERIALS AND METHODS}

\section{Chemicals and reagents}

The supplier of retinol, retinyl palmitate, retinyl acetate, 99.8 $\%$ acetonitrile (MeCN), $\mathrm{LiClO}_{4}$, paraffin oil and sodium dodecyl sulfate (SDS) was Sigma-Aldrich (Merck KGaA), Prague, Czech Republic. All these retinoids were crystalline with purity $\geq 95 \%$, and SDS with $\geq 99 \%$. Carbon powder type CR-5 (particle size $<5$ $\mu \mathrm{m})$ used for the preparation of carbon paste electrode (CPE) was a product of company Maziva Týn, Týn nad Vltavou, Czech Republic. $\mathrm{Al}_{2} \mathrm{O}_{3}$ powder (particle size about $1 \mu \mathrm{m}$ ) needed for polishing of glassy carbon electrode (GCE) surface was obtained from Metrohm, Prague, Czech Republic. Glacial acetic acid and sodium acetate from Merck, Darmstadt, Germany, and deionised water of $G=0.055 \mu \mathrm{S}$ from MilliQ system, distributed by Merck Millipore (Burlington, MA, USA) served for the preparation of $0.1 \mathrm{M}$ acetate buffer $(\mathrm{pH}=4.5)$.

\section{Carbon paste electrode preparation and modification}

CPE/SDS represents a common carbon paste electrode modified with high content of surfactant. In our case, $0.5 \mathrm{~g}$ graphite powder, paraffin oil ( $20 \%$ by mass), and SDS (30\% by mass) were homogenized for $20 \mathrm{~min}$. Afterwards, final mixture was placed into the cavity $(d=3 \mathrm{~mm})$ of piston-driven Teflon ${ }^{\circledR}$ holder from University of Pardubice, Czech Republic. Generally, freshly made CPEs, especially the modified ones, need some time (usually one day) prior to their employment in analysis due to so called "self-homogenization" phenomenon (23). After each measurement, the surface of the paste electrode was renewed by polishing with a wet filter paper.

\section{Pretreatment of glassy carbon electrode}

The surface of solid GCE ( $d=2 \mathrm{~mm}$ ) was polished with a wet pad containing $\mathrm{Al}_{2} \mathrm{O}_{3}$ powder (particle size about $1 \mu \mathrm{m}$ ) for 30 $s$ before each measurement. After that the surface was rinsed with distilled water. All equipment necessary for pretreatment of GCE was from company Metrohm.

\section{Apparatus}

Typical three-electrode electrochemical setup consisting of CPE/SDS or GCE (working), Ag/AgCl/3.0 M KCl (reference), and Pt wire (auxiliary) electrode was connected to the Autolab PGSTAT101 from Metrohm Autolab B.V., Utrecht, The Netherlands, operated by Nova v. 1.11.0 software (24). For calculation of the highest occupied molecular orbital (HOMO) and the lowest unoccupied molecular orbital (LUMO) energies, the DFT B3LYP $631 \mathrm{G}^{*}$ method with Spartan'16 software $(25,26)$ was used.

\section{Procedure}

Cyclic voltammetry (CV) was performed in acetonitrile containing $0.1 \mathrm{M} \mathrm{LiClO}_{4}$ for study of electrochemical behaviour of retinoids under following conditions: potential range from 0.2 to $+1.2 \mathrm{~V}$, step potential $\left(E_{\text {step }}\right) 2.5 \mathrm{mV}$ and scan rate $(v) 50 \mathrm{mV} / \mathrm{s}$. Differential pulse voltammetry (DPV) of retinol at both types of working electrodes was used under following conditions: the applied potential was from 0 to $+1.2 \mathrm{~V}, E_{\text {step }} 5 \mathrm{mV}$, potential of amplitude $\left(E_{\text {ampl }}\right) 25 \mathrm{mV}$, interval time $\left(t_{\text {int }}\right) 0.1 \mathrm{~s}$, equilibrium time $\left(t_{\mathrm{eq}}\right) 5 \mathrm{~s}$, and scan rate $50 \mathrm{mV} / \mathrm{s}$. All measurements were repeated minimally five times. If not stated otherwise, all changes in the experimental conditions are specified in the legends of the corresponding figures.

\section{Validation of developed voltammetric method}

The sensitivity is defined as the lowest detectable concentration of an analyte (limit of detection; LOD) and is given by a slope of corresponding calibration curve $(k)$. From a practical point of view, limit of quantification (LOQ) is a more important parameter than the theoretical value of LOD because it usually represents the lowest value of the calibration curve. Values of LOQ and LOD were calculated according to the following equations:

and

$$
\mathrm{LOQ}=10 \mathrm{~s} / \mathrm{k}
$$

$$
\text { LOD }=3 \mathrm{~s} / \mathrm{k}
$$

where $s$ is the standard deviation (Student's $t$-distribution) and $k$ is the arithmetic mean of minimally five voltammograms of $5.0 \mu \mathrm{M}$ retinol. 


\section{RESULTS AND DISCUSSION}

\section{Electrochemical behaviour of retinoids}

One of the aims of this work was to clarify the retinol oxidation mechanism because of discrepancies in literature. In 2010, it was published that the all-trans-retinol is irreversibly oxidized to retinal with participation of $2 \mathrm{e}^{-}$and $2 \mathrm{H}^{+}$ at GCE in $0.1 \mathrm{M} \mathrm{LiClO}_{4}$ water-ethanol medium (13). Nevertheless, it is necessary to state that authors proposed this reaction mechanism of retinol electrochemical oxidation based on the observation of only one oxidation peak at $+0.79 \mathrm{~V}$ (13). Later, the study of electrochemical behaviour of several retinoids in $\mathrm{CH}_{2} \mathrm{Cl}_{2}$ containing $0.2 \mathrm{M} \mathrm{Bu}_{4} \mathrm{NPF}_{6}$ using cyclic voltammetry (CV) at GCE confirmed that retinal, retinoic acid, retinyl palmitate and retinyl acetate are oxidized in similar manner as retinol (27). Hence, oxidation of retinol to retinal is unlikely because the above-mentioned retinoids do not contain free hydroxyl group (27). Meanwhile, Polish scientists studied electrochemical oxidation of retinyl propionate at Pt electrode in $\mathrm{MeCN}$ containing 0.1 $\mathrm{MBu}_{4} \mathrm{NClO}_{4}$ (28). The comparison of FTIR spectra and calculation of electron density suggested that electrochemical oxidation probably takes place on $\mathrm{C} 3$ position of cyclohexene ring with participation of $2 \mathrm{e}^{-}$and $\mathrm{H}^{+}(28)$.

This investigation studied electrochemical behaviour of retinol, retinyl acetate and retinyl palmitate in nonaqueous, aqueous-organic ( $50 \% \mathrm{MeCN}$ containing $0.1 \mathrm{M} \mathrm{LiClO}_{4}$ ) and pure aqueous medium ( $0.1 \mathrm{M}$ acetate buffer, $\mathrm{pH}=4.5$ ) by cyclic voltammetry in order to confirm or disprove the previous claims $(12,13,28)$. Due to lipophilic character of all retinoids, measurements in the aqueous medium were carried out in the adsorbed state (29).

$\mathrm{CV}$ showed that all studied esters of retinol always provide only one oxidation peak at about $+0.8 \mathrm{~V}$ in all tested media. Unlike this, retinol behaves like this only in adsorbed state at GCE in pure aqueous electrolytes (Fig. 1). In other cases, two oxidation peaks (Fig. 2) are visible, which has already been described (30).

The mechanism of electrode reaction can be predicted based on quantum chemical calculations. In the narrower sense, the distribution of the electron charges in certain molecule determines individual reaction centres because, in general, molecular orbitals with an excess of electrons are more easily oxidized than those with a deficiency. The prediction of electrochemical behaviour of retinol and other retinoids can be therefore facilitated by theoretical calculation of HOMO and LUMO. The obtained results suggest that an electrochemical oxidation is delocalized over carbon atoms of the five conjugated double bonds (C5-C14), where the highest current density was present. For comparison, Fig. 3 shows electron density plots of retinol and retinyl acetate. Both compounds gave $E(\mathrm{HOMO})=5.0 \mathrm{eV}$. It is evident that hydroxy or ester functional group is not energy efficient for the electrochemical oxidation.

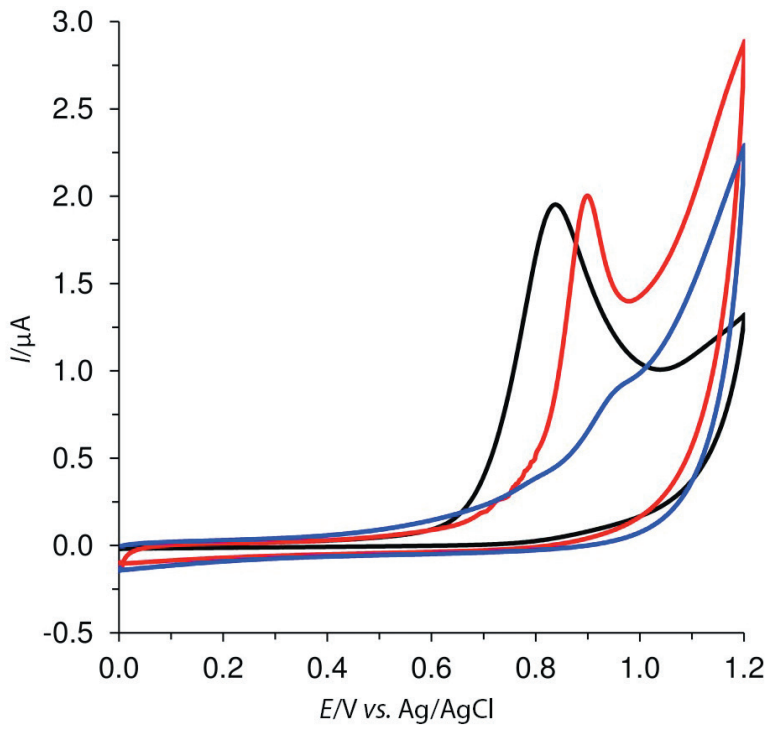

Fig. 1. Cyclic voltammograms of $0.5 \mathrm{mM}$ retinol (black), retinyl acetate (red), and retinyl palmitate (blue) adsorbed at glassy carbon electrode surface from $30 \% \mathrm{MeCN}$ solution at $400 \mathrm{rpm}$ for $10 \mathrm{~min}$, then measured in $0.1 \mathrm{M}$ acetate buffer at $\mathrm{pH}=4.5$ and scan rate 100 $\mathrm{mV} / \mathrm{s}$

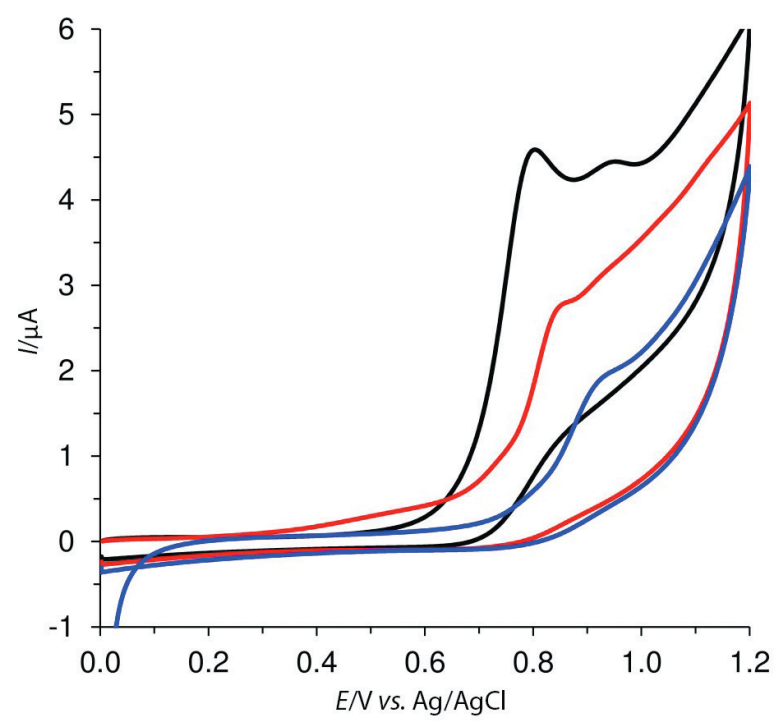

Fig. 2. Cyclic voltammograms of $0.5 \mathrm{mM}$ retinol (black), retinyl acetate (red), and retinyl palmitate (blue) obtained at glassy carbon electrode in the mixture of pure $\mathrm{MeCN}$ and $0.1 \mathrm{M}$ acetate buffer at $\mathrm{pH}=4.5(1: 1)$ and scan rate $100 \mathrm{mV} / \mathrm{s}$

Generally, it is known that the $\mathrm{CV}$ is not as sensitive technique as DPV, but it dominates in the study of electrochemical processes. Moreover, it is necessary to consider that multiple peaks may merge in one in the $\mathrm{CV}$, whereas they can be clearly recognised in DPV. The oxidation of all tested retinoids at GCE occurred in three steps (measured up to a potential value $+1.2 \mathrm{~V}$ ) and is probably irreversible (Fig. 4-Fig. 6). These findings are consistent with previous electrochemical studies of retinoids $(28,31)$, especially of all-trans-retinoic acid 
a)

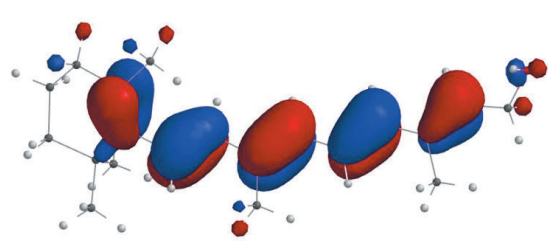

b)
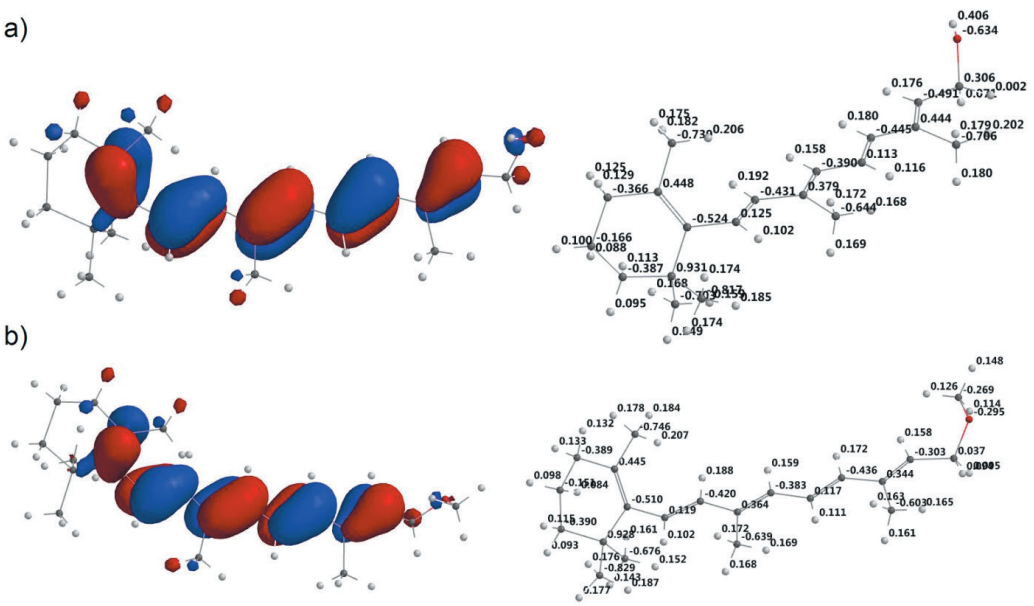

Fig. 3. The highest occupied molecular orbital (HOMO ) distributions and electron density plots of: a) retinol and b) retinyl acetate

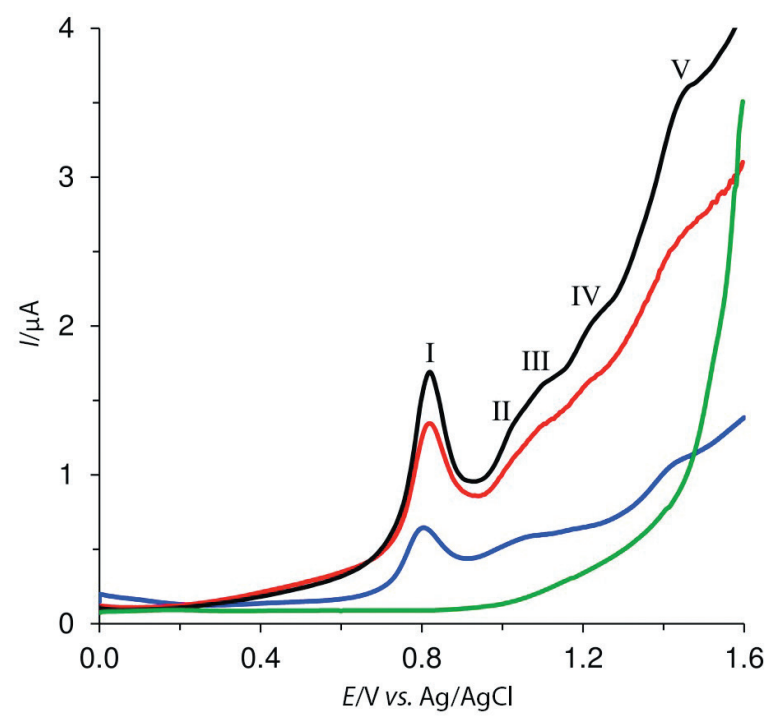

Fig. 4. Differential pulse voltammograms of 0 (green) and $0.5 \mathrm{mM}$ retinyl acetate obtained at glassy carbon electrode in the $80 \% \mathrm{MeCN}$ containing $0.1 \mathrm{M} \mathrm{LiClO}_{4}$ at scan rates: 5 (blue), 50 (red) and $200 \mathrm{mV} / \mathrm{s}$ (black)

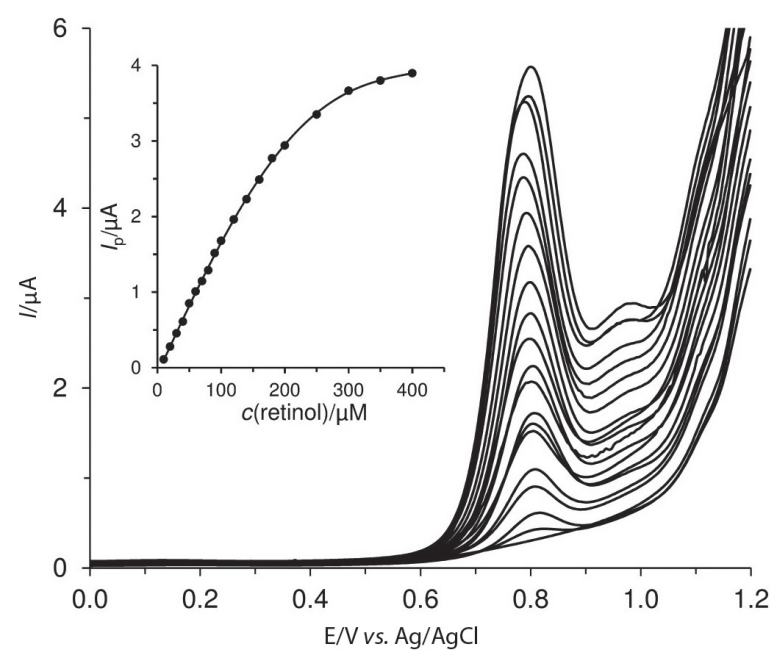

Fig. 5. Differential pulse voltammograms of $0-400 \mu \mathrm{M}$ vitamin $A_{1}$ with appropriate calibration curve performed at carbon paste electrode modified with sodium dodecyl sulfate in supporting electrolyte 0.1 $\mathrm{M} \mathrm{LiClO}_{4}$ in $99.8 \% \mathrm{MeCN}_{\text {. }}$ = $=$ peak current

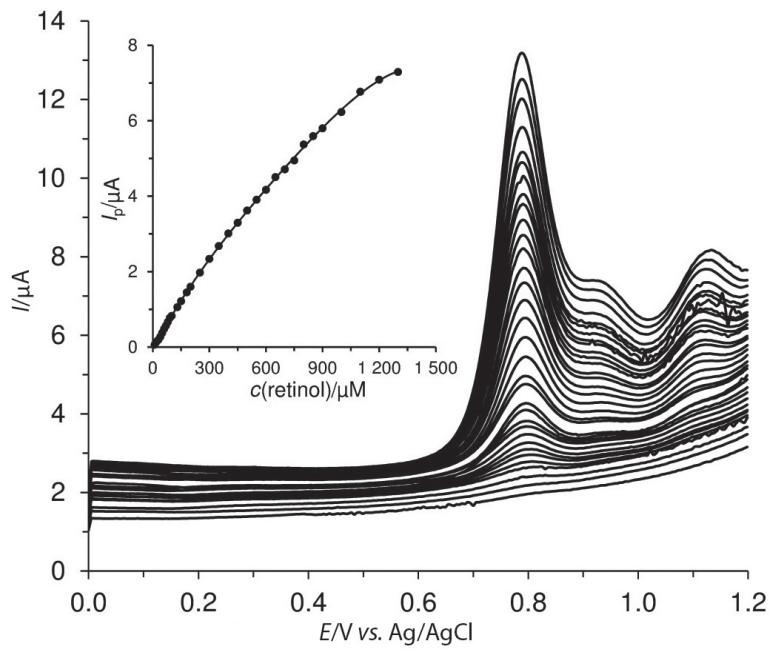

Fig. 6. Differential pulse voltammograms of 0-1.3 mM vitamin $A_{\text {, with }}$ appropriate calibration curve performed at solid glassy carbon electrode in supporting electrolyte $0.1 \mathrm{M} \mathrm{LiClO}_{4}$ in $99.8 \% \mathrm{MeCN} . I_{\mathrm{p}}=$ peak current

(32). Oddly enough, when the potential range was extended to $+1.6 \mathrm{~V}$, other two oxidation processes appeared (Fig. 4).

It has to be mentioned that broader peaks usually appear at the CPE/SDS rather than at solid GCE. Moreover, third oxidation peak (III) was quite difficult to recognize due to electrolyte discharge (compare Fig. 5 with Fig. 6). Finally, we conclude that the all-trans-retinol is probably not electrochemically oxidized to all-trans-retinal. Delocalized electron system does not allow to determine with certainty which carbon of the conjugate system is oxidized primarily. Even so, the proposal of Masek et al. (28) is considered as the most probable.

Optimization of surfactant-modified carbon paste electrode

Several modified CPE/SDS always containing $20 \%$ (by mass) paraffin oil and different amounts of SDS were prepared to study the effect of the used surfactant. During laboratory preparation of CPEs, we observed that the pasting character of electrode material increased with higher content of SDS, so 
we characterized them by measuring the ohmic resistance $(R)$. In this study, it was clear that higher amount of the modifier caused an increasing ohmic resistance as following: approx. $6.5,10.2,16.8$ and $53.7 \Omega$ for $5,10,20$ and $30 \%$ (by mass) SDS.

Despite the highest ohmic resistance observed, the CPE containing $30 \%$ SDS appeared the most suitable choice due to the lowest obtained background current response (approx. $1 \mu \mathrm{A})$. Explanation can be the mechanical stability of conventional carbon paste. In the presence of organic solvents, carbon particles are pulled out of the electrode material. The effect of organic solvent increases with decreasing surfactant content, which leads to electric contact deterioration of carbon particles and a rise of background current to approx. 5.2 and 9.4 $\mu \mathrm{A}$ with 10 and $5 \%$ (by mass) SDS.

\section{Electrochemical determination of retinol}

From the analytical point of view, it is important to know that it is not possible to determine individual retinoids due to close values of oxidation potentials. For this reason, it is possible to express only the sum of all retinoids present in the sample and determine as total content of vitamin A.

At the beginning, it was necessary to find optimum working conditions of used voltammetric technique. Standard values of DPV parameters: $E_{\text {ampl }}=25 \mathrm{mV}, E_{\text {step }}=5 \mathrm{mV}, t_{\text {int }}=0.1 \mathrm{~s}$ and $v=50 \mathrm{mV} / \mathrm{s}$ in voltammetric determination of retinol were chosen as optimum because any change of the mentioned values did not help to achieve significant increase of sensitivity (peak I in Fig. 4). Additionally, it was evident that using higher values of scan rate dramatically increased the noise of base line current response, which can negatively affect the final analytical parameters (not shown).

Calibration graphs for both used working electrodes were constructed by using aliquots of retinol stock solution $(0.01 \mathrm{M}$ retinol in pure $\mathrm{MeCN}$ ) with the addition of $20 \mathrm{~mL}$ of $0.1 \mathrm{M} \mathrm{LiClO}_{4}$ in $99.8 \% \mathrm{MeCN}$ as supporting electrolyte into voltammetric cell.

Nevertheless, it was clear that linearity of calibration curve at CPE/SDS:

$$
I_{\mathrm{p}}=0.0161 \mathrm{c}-0.0026
$$

ranged from 1.5 to $180 \mu \mathrm{M}$ retinol with $\mathrm{R}^{2}=0.9955$ (Fig. 5), which is more than three times shorter than at solid GCE:

$$
I_{\mathrm{p}}=0.0083 \mathrm{c}-0.0256
$$

ranging from 4.4 to $700 \mu \mathrm{M}$ retinol with $\mathrm{R}^{2}=0.9953$ (Fig. 6), where $I_{\mathrm{p}}$ is peak current and $c$ is concentration of all-trans-retinol. Almost three times lower value of detection limit (LOD) was obtained at CPE/SDS than at solid GCE.

Generally, accuracy represents accordance between the real concentration of analyte and that found by an analytical method used. This analytical parameter is often verified using a model sample (recovery), declared amount, or by comparison with a reference method always based on another physicochemical principle. Recovery study used $10 \mathrm{~mL}$ of 0.1 $\mathrm{M} \mathrm{LiClO}_{4}$ in $99.8 \% \mathrm{MeCN}$ and $40 \mu \mathrm{M}$ retinol. This analysis was based on standard addition method (not shown) with minimally four $10-\mu \mathrm{L}$ additions of $0.01 \mathrm{M}$ retinol. Herein, it is necessary to mention that the standard addition method can operate under the condition of a very low intercept of calibration curve $(q)$, which the developed method fully meets.

Surprisingly, a little better recovery values were evident in the assay obtained on the same surface than if it was constantly restored after each measurement. The recovery values were $95.0 \%$ at CPE/SDS $I_{\mathrm{p}}=(38 \pm 1.5) \mu \mathrm{M}$ and $94.3 \%$ at GCE $I_{\mathrm{p}}=(37.7 \pm 1.9) \mu \mathrm{M}$ with relative standard deviations of 3.9 and $5.1 \%$, respectively.

For completeness of comparison, Table 1 (11-15) shows all conventional electrochemical methods for determination of vitamin $A_{1}$ developed since 1974, and lists type of electrode material, chosen electrochemical technique, composition of used electrolyte, linear range, and limit of detection for each method. This important comparison shows the significant improvement in the analytical parameters for both types of used electrodes. All previous methods did not achieve so low detection limit as the economically advantageous CPE/SDS. Only square wave voltammetric method at GCE modified with multi-wall carbon nanotube polymer composite in Triton X-100 solution (15) provides nearly similar analytical parameters. It is speculative that the developed voltammetric method utilizing the CPE modified with SDS should find a wide application in the food analysis, especially for margarine (33), food supplements, fish oil, cosmetics (34), pharmaceutical products, etc. The matrix of these samples is usually completely soluble or at least

\begin{tabular}{|c|c|c|c|c|c|}
\hline Sensor & Method & Electrolyte & Linear range/M & LOD/M & Ref. \\
\hline $\mathrm{CPE} / \mathrm{CW} / \mathrm{SO}$ & LSV & $75 \% \mathrm{EtOH} / 0.01 \mathrm{M} \mathrm{H}_{2} \mathrm{SO}_{4}$ & $5.0 \cdot 10^{-5}-1.0 \cdot 10^{-3}$ & - & (11) \\
\hline PtE & LSV & $0.1 \mathrm{M} \mathrm{HClO}_{4} / \mathrm{MeCN}$ & $8.22 \cdot 10^{-5}-1.08 \cdot 10^{-3}$ & - & (12) \\
\hline $\mathrm{PtE}$ & LSV & $0.1 \mathrm{M} \mathrm{CH}_{3} \mathrm{COONa} / \mathrm{MeCN}$ & $7.54 \cdot 10^{-4}-1.66 \cdot 10^{-3}$ & - & (13) \\
\hline GCE & $\mathrm{CV}$ & $0.1 \mathrm{M} \mathrm{LiClO}_{4} / 0.1 \mathrm{mM}$ SDS & $2.94 \cdot 10^{-5}-9.80 \cdot 10^{-4}$ & $1.5 \cdot 10^{-5}$ & (13) \\
\hline GCE & LSV & $0.1 \mathrm{M} \mathrm{HClO}_{4} / \mathrm{MeCN}$ & $1.3 \cdot 10^{-4}-1.2 \cdot 10^{-3}$ & $9.5 \cdot 10^{-5}$ & (14) \\
\hline GCE/MWCNTs & LSV & $0.1 \mathrm{M} \mathrm{HClO}_{4} / \mathrm{MeCN}$ & $6.5 \cdot 10^{-5}-1.5 \cdot 10^{-3}$ & $4.0 \cdot 10^{-5}$ & (14) \\
\hline GCE/MWCNTs/PPH & SWV & Triton X-100 & $5.0 \cdot 10^{-6}-2.0 \cdot 10^{-4}$ & $8.0 \cdot 10^{-7}$ & (15) \\
\hline GCE & DPV & $0.1 \mathrm{M} \mathrm{LiClO}_{4} / \mathrm{MeCN}$ & $4.4 \cdot 10^{-6}-7.0 \cdot 10^{-4}$ & $1.3 \cdot 10^{-6}$ & This paper \\
\hline CPE/SDS & DPV & $0.1 \mathrm{M} \mathrm{LiClO} / 4 / \mathrm{MeCN}$ & $1.5 \cdot 10^{-6}-1.8 \cdot 10^{-4}$ & $4.6 \cdot 10^{-7}$ & This paper \\
\hline
\end{tabular}

Table 1. Comparison of conventional voltammetric methods for retinol determination

$\mathrm{LOD}=$ limit of detection, $\mathrm{CPE}=$ carbon paste electrode, $\mathrm{CW}=$ ceresin wax $(5 \%), \mathrm{SO}=$ silicone oil, $\mathrm{LSV}=$ linear sweep voltammetry, PtE=stationary platinum electrode, GCE=glassy carbon electrode, $C V=$ cyclic voltammetry, $\mathrm{SDS}=$ =sodium dodecyl sulfate, MWCNTs=multi-walled carbon nanotubes, $\mathrm{PPH}=$ poly $\left(2,2^{\prime}-(1,4\right.$-phenylenedivinylene)-bis-8-hydroxyquinaldine), SWV=square wave voltammetry, DPV=differential pulse voltammetry 
partially soluble in pure acetonitrile. However, complicated and time-consuming sample preparation before each analysis should draw attention in more complex foodstuffs.

\section{CONCLUSIONS}

In this paper, the evaluation of cyclic voltammetry of retinol with its esters used a carbon paste electrode modified with sodium dodecyl sulfate (CPE/SDS) and glassy carbon electrode (GCE) in various types of media to clarify electrochemical reaction mechanism of retinol. We found that oxidation of all tested retinoids takes several steps, which corresponds to oxidation in delocalized electron system of conjugated double bonds. Due to nearly identical values of peak potentials, only the sum of all retinoids present in the sample is possible to determine and express as total content of vitamin A. The obtained results of electroanalysis show that differential pulse voltammetry (DPV) at $\mathrm{CPE} / \mathrm{SDS}$ performed in the nonaqueous media represents completely suitable electroanalytical method for direct voltammetric determination of retinol and provides similar electrochemical performance to the commonly used GCE. Furthermore, it is necessary to state that this method achieved significantly better value of the detection limit than the already developed conventional electroanalytical methods. The data also confirm the fact that the presence of surfactant in CPE allows to use it in electrochemical measurements in pure organic solvents.

\section{ACKNOWLEDGEMENTS}

Authors gratefully acknowledge the support received by the Faculty of Chemical Technology, University of Pardubice, Czech Republic (project no. SGFChT 2017/001)

\section{REFERENCES}

1. Palafox NA, Gamble MV, Dancheck B, Ricks OM, Briand K, Semba RD. Vitamin A deficiency, iron deficiency, and anemia among preschool children in the Republic of the Marshall Islands. Nutrition. 2003;19(5):405-8.

https://doi.org/10.1016/S0899-9007(02)01104-8

2. Xue X, You J, He P. Simultaneous determination of five fat-soluble vitamins in feed by high-performance liquid chromatography following solid-phase extraction. J Chromatogr Sci. 2008;46(4):345-50.

https://doi.org/10.1093/chromsci/46.4.345

3. Gregory III JF. Vitamins. In: Damodaran S, Parkin KL, Fennema OR, editors. Fennema's food chemistry. Boca Raton, FL, USA: CRC Press, 2007. pp. 454-60.

4. Barua AB, Furr HC, Olson JA, Van Breemen RB. Vitamin A and carotenoids. In: De Leenheer AP, Lambert WE, Van Bocxlaer $J F$, editors. Modern chromatographic analysis of vitamins, vol. 84. New York, NY, USA: Marcel Dekker; 2000. pp. 1-69.

5. Paixa JA, Campos JM. Determination of fat soluble vitamins by reversed-phase HPLC coupled with UV detection: A guide to the explanation of intrinsic variability. J Liq
Chromatogr Relat Technol. 2003;26(4):641-63.

https://doi.org/10.1081/JLC-120017913

6. Vitamins and other nutrients. In: Horwitz W, Latimer GW, editors. Official methods of analysis of AOAC International. Gaithersburg, Maryland, USA: AOAC International; 2005. pp. 1045-114.

7. Barua $A B$, Kostic D, Olson JA. New simplified procedures for the extraction and simultaneous high-performance liquid chromatographic analysis of retinol, tocopherols and carotenoids in human serum. J Chromatogr B. 1993;617(2):257-64. https://doi.org/10.1016/0378-4347(93)80496-Q

8. Chen L, Liu Z, Kang X, Zhou X, Zheng S, Gu Z. Determination of fat-soluble vitamins in food and pharmaceutical supplements using packed-fibber solid phase extraction (PFSPE) for sample preconcentration/clean-up. Procedia Environ Sci. 2011;8:588-95.

https://doi.org/10.1016/j.proenv.2011.10.091

9. Delgado Zamarreño MM, Sanchez Perez A, Sanchez Rodriguez M, Gomez Perez MC, Hernandez Mendez J. Determination of fat-soluble vitamins in yogurt by HPLC with electrochemical detection. Talanta. 1996;43(9):1555-63. https://doi.org/10.1016/0039-9140(96)01939-X

10. Ma Y, Wu Z, Furr HC, Lammi-Keefe C, Craft NE. Fast minimicroassay of serum retinol (vitamin A) by capillary zone electrophoresis with laser-excited fluorescence detection. J Chromatogr B. 1993;616(1):31-7.

https://doi.org/10.1016/0378-4347(93)80468-J

11. Atuma SS, Lindquist J, Lundstrom K. The electrochemical determination of vitamin A, part I. Voltammetric determination of vitamin A in pharmaceutical preparations. Analyst. 1974;99(1183):683-9.

https://doi.org/10.1039/AN9749900683

12. Budnikov GK, Ziyatdinova GK, Gil'metdinova DM. Determination of some liposoluble antioxidants by coulometry and voltammetry. J Anal Chem. 2004;59(7):654-8. https://doi.org/10.1023/B:JANC.0000035278.20459.9e

13. Ziyatdinova G, Giniyatova E, Budnikov H. Cyclic voltammetry of retinol in surfactant media and its application for the analysis of real samples. Electroanalysis. 2010;22(22):2708-13. https://doi.org/10.1002/elan.201000358

14. Ziyatdinova G, Morozov M, Budnikov H. MWNT-modified electrodes for voltammetric determination of lipophilic vitamins. J Solid State Electrochem. 2012;16(7):2441-7. https://doi.org/10.1007/s10008-011-1581-7

15. Filik H, Avan AA, Aydar S. Simultaneous electrochemical determination of a-tocopherol and retinol in micellar media by a poly(2,2'-(1,4-phenylenedivinylene)-bis-8-hydroxyquinaldine)-multiwalled carbon nanotube modified electrode. Anal Lett. 2016;49(8):1240-57. https://doi.org/10.1080/00032719.2015.1094665

16. Švancara I, Ogorevc B, Hočevar SB, Vytřas K. Perspectives of carbon paste electrodes in stripping potentiometry. Anal 
Sci. 2002;18(3):301-5.

https://doi.org/10.2116/analsci.18.301

17. Švancara I, Vytřas K, Renger F, Smyth MR. Application of carbon paste electrodes in highly methanolic solutions. Electrochim Acta. 1992;37(8):1355-61.

https://doi.org/10.1016/0013-4686(92)87007-M

18. Marcoux LS, Prater KB, Prater BG, Adams RN. A nonaqueous carbon paste electrode. Anal Chem. 1965;37(11):1446-7. https://doi.org/10.1021/ac60230a047

19. Švancara I, Kalcher K, Walcarius A, Vytřas K. Electroanalysis with carbon paste electrodes. Boca Raton, FL, USA: CRC Press; 2012.

20. Sýs M, Metelka R, Stočes M, Vytřas K. Electrochemical properties of a-tocopherol in aqueous electrolytes after its previous extraction into the glassy carbon paste from aqueous-acetonic mixture. Monatsh Chem 2016; 147(1):31-8. https://doi.org/10.1007/s00706-015-1620-7

21. Hart JP, Norman MD, Lacey CJ. Voltammetric behaviour of vitamins D2 and D3 at a glassy carbon electrode and their determination in pharmaceutical products by using liquid chromatography with amperometric detection. Analyst. 1992; 117(9):1441-45.

https://doi.org/10.1039/AN9921701441

22. Sýs M, Metelka R, Mikysek T, Vytřas K. Improvement of enzyme carbon paste-based biosensor using carbon nanotubes for determination of water-soluble analogue of vitamin E. Chem Pap. 2015; 69(1):150-7. https://doi.org/10.2478/s11696-014-0608-9

23. Kalcher K, Kauffmann JM, Wang J, Švancara I, Vytřas K, Neuhold C, Yang Z. Sensors based on carbon paste in electrochemical analysis: A review with particular emphasis on the period 1990-1993. Electroanalysis. 1995;7(1):5-22.

https://doi.org/10.1002/elan.1140070103

24. Nova, v. 1.11.0. Utrecht, The Netherlands: Metrohm Autolab B.V.; 2014. Available from: http://www.ecochemie.nl/news/ NOVA_1.11.html.

25. Spartan'16. Irvine, CA, USA:Wavefunction, Inc.; 2018. Available from: https://www.wavefun.com/.

26. Kocábová J, Fiedler J, Degano I, Sokolová R. Oxidation mechanism of flavanone taxifolin. Electrochemical and spectroelectrochemical investigation. Electrochim Acta.
2016;187:358-63.

https://doi.org/10.1016/j.electacta.2015.11.077

27. Tan YS, Urbančok D, Webster RD. Contrasting voltammetric behaviour of different forms of vitamin A in aprotic organic solvents. J Phys Chem B. 2014;118(29):8591-600.

https://doi.org/10.1021/jp505456q

28. Masek A, Chrzescijanska E, Zaborski M. Voltammetric and FTIR spectroscopic studies of the oxidation of retinyl propionate at Pt electrode in non-aqueous media. Int J Electrochem Sci. 2014;9:6809-20.

29. Sýs M, Žabčíková S, Červenka L, Vytřas K. Adsorptive stripping voltammetry in lipophilic vitamins determination. Potr S J F Sci. 2016;10(1):260-4. https://doi.org/10.5219/587

30. Wring SA, Hart JP, Knight DW. Voltammetric behaviour of all-trans-retinol (vitamin A1) at glassy carbon electrode and its high-performance liquid detection in human serum using high-performance liquid chromatography with electrochemical detection. Analyst. 1988;113(12):1785-9.

https://doi.org/10.1039/AN9881301785

31. Sýs M, Žabčíková S, Červenka L, Vytřas K. Comparison of adsorptive with extractive stripping voltammetry in electrochemical determination of retinol. Potr S J F Sci. 2017;11(1):96-105.

https://doi.org/10.5219/713

32. da Silva FLO, da Silva Tinoco LM, Ferreira LAM, Malagutti AR, Carneiro G. Determination of all-trans retinoic acid loaded in solid lipid nanoparticles by differential pulse voltammetry at glassy carbon electrode. Electrochim Acta. 2015;182:929-34.

https://doi.org/10.1016/j.electacta.2015.10.018

33. Sýs M, Švecová B, Švancara I, Metelka R. Determination of vitamin $\mathrm{E}$ in margarines and edible oils using square wave anodic stripping voltammetry with a glassy carbon paste electrode. Food Chem. 2017;229:621-7. https://doi.org/10.1016/j.foodchem.2017.02.068

34. Žabčíková S, Nallbani A, Sýs M, Mikysek T, Červenka L. Square wave voltammetry at carbon paste electrode modified with surfactant for alpha tocopheryl acetate determination in cosmetics. Potr S J F Sci. 2018;12(1):135-42. https://doi.org/10.5219/10.5219/881 